\title{
Generic Drugs Regulations and Registration in Indonesia, Malaysia and Vietnam: A Drug Regulatory Case Study
}

\author{
Sandeep DS ${ }^{1, *}$, Sowmya CR' ${ }^{1}$ Anoop Narayanan V', Gowrav MP² \\ 'Department of Pharmaceutical Regulatory Affairs, NGSM Institute of Pharmaceutical Sciences, NITTE (Deemed to be University), Deralakatte, \\ Mangaluru, Karnataka, INDIA. \\ 2Department of Pharmaceutics, JSS College of Pharmacy, JSS Academy of Higher Education and Research, SS Nagara, Mysuru, Karnataka, INDIA.
}

\begin{abstract}
Objectives: The present study describes the generic drug regulations and registration process in three ASEAN countries Indonesia, Malaysia and Vietnam. Methods: For the current study, the information has been taken from guidelines set forth by the respective regulatory authorities of three selected ASEAN countries concerning the technical guidelines available for generic drugs. Relevant data were also collected from regulatory websites and articles from reputed journals. Results: The process of site evaluation, pre-submission, dossier screening, registration and regulatory approval of generic drugs in Indonesia and Vietnam is quite similar concerning the regulations framed by their respective drug regulatory authorities. In Malaysia, Drug Control Authority accepts only web-based online submissions. The applicant for product registration must be registered with the Malaysian Register of Business (ROB) and should become a quest
\end{abstract}

member at the NPCB website. Conclusion: From our studies relevant to the regulatory perspectives, it is concluded that Malaysia had well-framed drug regulations for generic drugs compared to Indonesia and Vietnam. Key words: ACTD, ASEAN, Generic drugs, DCA, ROB, NPCB, Dossier.

\section{Correspondence}

Dr. Sandeep DS, M.Pharm, Ph.D

Assistant Professor, Department of Pharmaceutics, NGSM Institute of Pharmaceutical Sciences, NITTE (Deemed to be University), Paneer, Deralakatte, Mangaluru-575018, Karnataka, INDIA.

Email id: sandypharama@gmail.com

DOI: 10.5530/jyp.2022.14.7

\section{INTRODUCTION}

\section{Generics in ASEAN region}

Generic drugs concept has gained more attention in the pharmaceutical market with enhanced accessibility and affordability of providing medicinal products to most patients with good quality, safety and efficacy. It has also been observed that half of the medicines available were manufactured as generic drugs, but they cover only $18 \%$ of the total margin. ${ }^{1}$

The Association of Southeast Asian Nations (ASEAN) region was framed in the year 1967. ASEAN region is composed of 10 countries with common drug regulations, called ASEAN regulations which came into force by $2008 .{ }^{2}$ Presently, the ASEAN countries have achieved significant progress towards Universal Health Coverage (UHC), a concept proposed by WHO. However, all regions in ASEAN countries were facing several barriers to meet the UHC adoption due to a lack of harmonized and stringent drug regulations. In ASEAN, for the compilation and submission of a dossier for generic drugs, ACTD (ASEAN- CTD) format is recommended. ${ }^{3,4}$

\section{METHODS}

In the present study, three ASEAN countries, namely Indonesia, Malaysia, and Vietnam, were selected to compare the generic drug regulatory strategies. The data concerned with generic drug regulation was collected from literature and information from regulatory agency websites. Appropriate guidelines were assimilated, suitable and required guidelines were extracted. The similarities and differences among the selected three ASEAN regions were understood. Then final compilation was made according to the format, which will ease the single time dossier submission for multiple regions.

\section{CTD and ACTD}

All the countries follow the ASEAN Common Technical Dossier (ACTD) to compile and submit a dossier for generic drug products in the ASEAN region. ACTD is generally derived from the standard format ICH-CTD. "ACTD is a regulatory document for the preparation and compilation of required CTD applications which are submitted to concerned ASEAN regulatory authority for the registration of pharmaceuticals for human use." ACTD is identical to the ICH-CTD but differs in several modules. In general, CTD is categorized into five modules. In contrast, ACTD comprises only four since the reference applications received by ASEAN countries have already been approved in other regulated countries around the world (EU, UK and USA). Assessment of the sections is focused primarily on overviews and summaries. Even though the regulatory environment is similar, the approval process for drugs differs in all ASEAN countries for their drug regulations. ${ }^{5,6}$

\section{RESULTS}

\section{ACTD format and ACTD modules}

The ACTD triangle is represented in Figure 1.

\section{Generic drug regulations and registration process in Indonesia}

Indonesia has a population of about 272.25 million. The drug regulatory authority in Indonesia is the National Agency of Drugs and Food Control (NA-DFC), located in Jakarta, the capital of Indonesia. For the submission of generic drugs to be approved, the ACTD format is followed in Indonesia. ${ }^{7}$

The generic drug registration and approval process in Indonesia is described in Figure 2. 


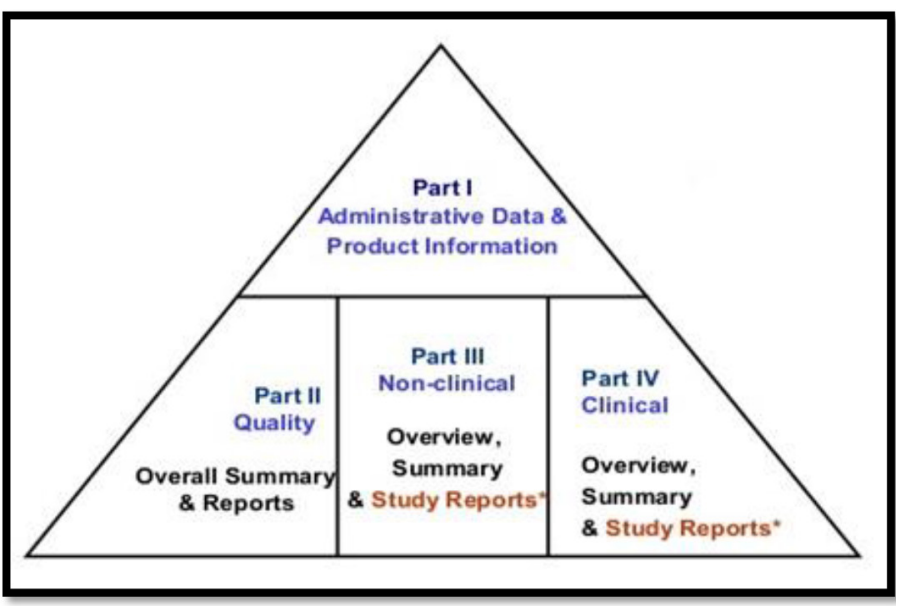

Figure 1: ACTD triangle showing different modules applicable.

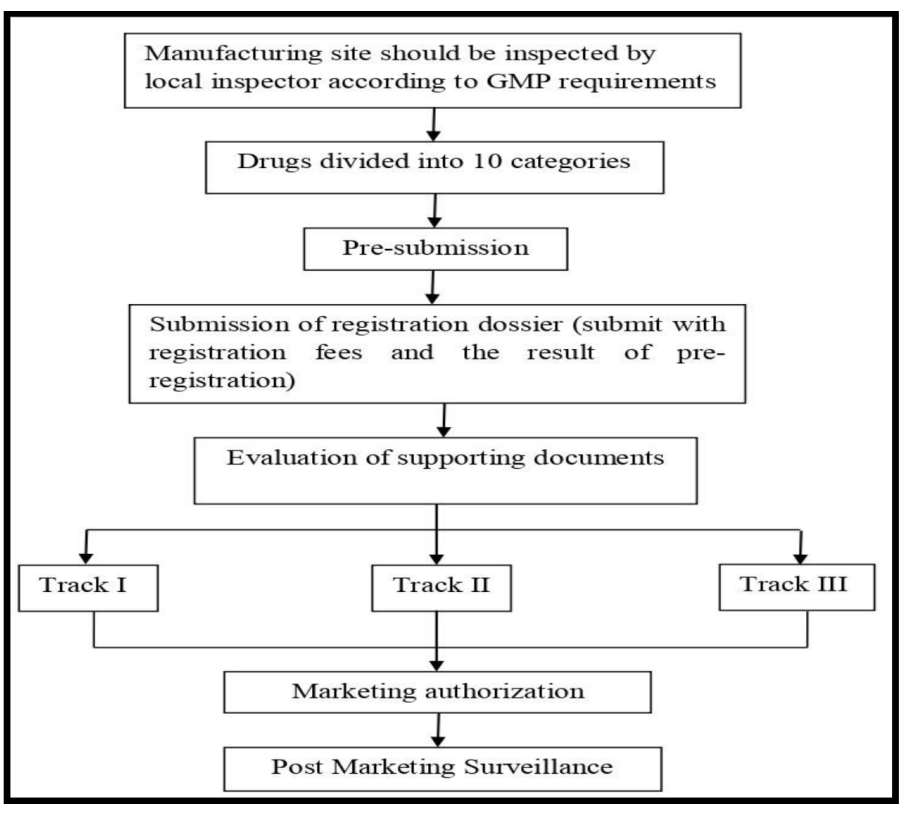

Figure 2: Generic drug registration process in Indonesia.

\section{Generic drugs regulations and registration process in Malaysia}

Malaysia geographically has an area of 329,847 sq. km with a population of about 33.36 million. In Malaysia, various authorities regulate the functions associated with drug approval. The Ministry of Health Malaysia regulates the laws and regulations related to health care products. Drug Control Authority (DCA) is responsible for registering pharmaceutical and cosmetic products and provides the license for the manufacturing, importing, and for the export of drug products. DCA also monitors the quality and adverse drug reactions of drug products marketed in Malaysia. ${ }^{8}$ The National Pharmaceutical Control Bureau (NPCB) is responsible for monitoring the operations of drug registration, notification and post-market surveillance activities. The regulatory submission of a dossier in Malaysia should be made only in the ACTD format. In Malaysia, there are three regulatory amendments made for the regulatory control of drugs and cosmetics, which include

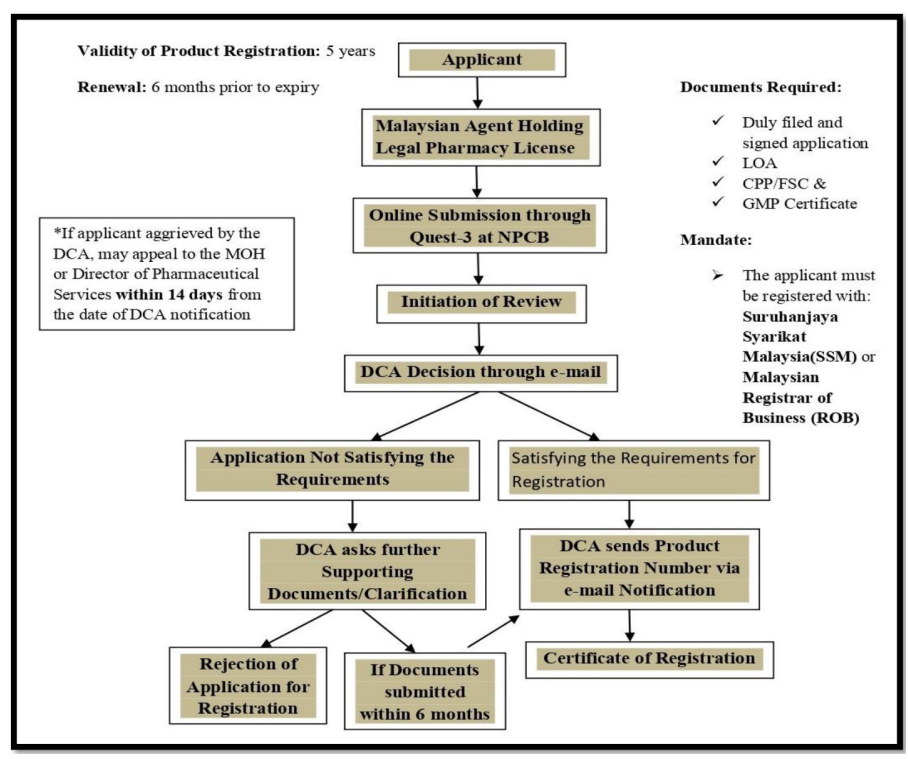

Figure 3: Generic drug registration and approval process in Malaysia.

the Medicines (Advertisement and Sale) Act 1956, Control of Drugs and Cosmetics Regulations 1984 and Sales of Drug Act 1952. ${ }^{9}$

The generic drugs approval process in Malaysia is depicted in Figure 3.

\section{Generic drugs regulations and registration process in Vietnam}

Vietnam has a population of 96.46 million, with almost $16 \%$ of the drug market share worldwide. Presently, Vietnam is looking to improve its legal system to make a favorable environment for the multi-sector market economy. In recent years, many drug regulations have been implemented and passed to make legal aspects comply with international agreements' requirements and to meet them under WTO membership. In Vietnam, the drug products are regulated by the Drug Administration of Vietnam (DAV), which has amended different laws, such as The Pharmacy Law 2005, The Health Insurance Law 2008 and The Ordinance on Private Medical and Pharmaceutical Practice 2003, to enhance social welfare. The director and deputy director of DAV are appointed by Vietnam's Ministry of Health $(\mathrm{MoH}) .{ }^{10}$ The DAV director is responsible for all the activities related to the drug regulation and approval process. The deputy director performs his functions under the guidance of the director of DAV. For the dossier submission of generic and other drugs in Vietnam, the ACTD format is only recommended and acceptable for final approval. The generic drugs registration process in Vietnam by DAV is represented in Figure 4.

\section{DISCUSSION}

For generic drug registration in Indonesia, the applicant must submit a drug registration application to the Head of the National Agency. The relevant documents of regulatory information can be prepared in English or Bahasa- Indonesian language and can be submitted to the drug approval authority. Drug products meant for export are exempted from having labels in the Bahasa language, and the labeling can be done only in English. In Indonesia, it is required to submit the dossier in a floppy disc and the receipt of payment for the scrutiny. ${ }^{11}$

The registration-dossier requirements for drug products and active ingredients should be provided in Electronic Information Standard format (STENIL- Standard Informasi Elecktronic) written in floppy 


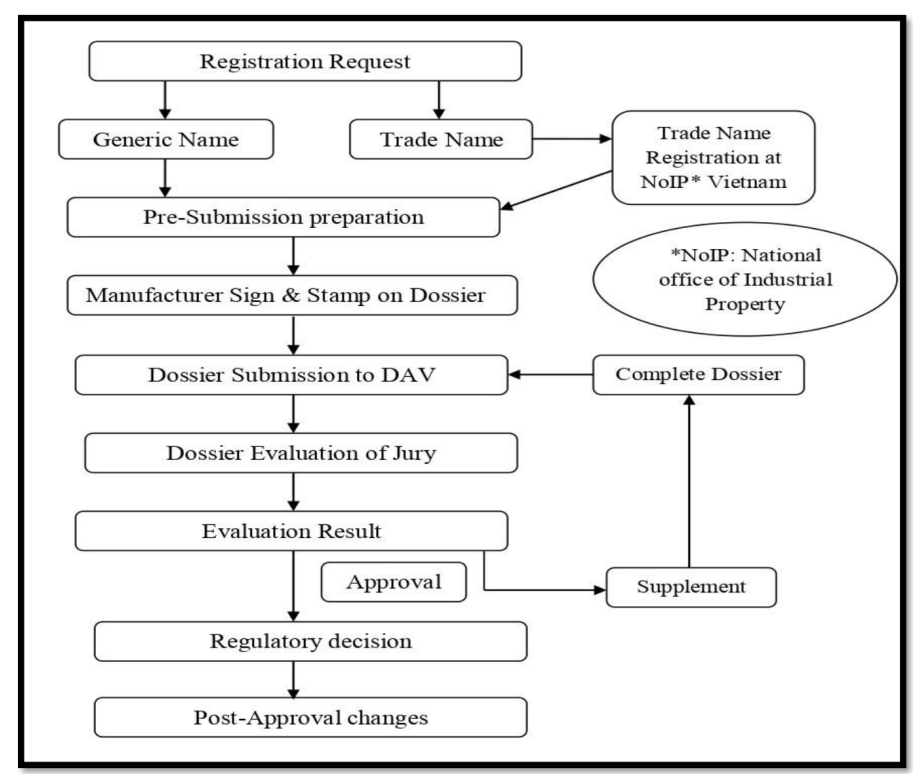

Figure 4: Generic drug approval process in Vietnam.

discs. The provided data must be made in the different forms, Form A, Form B21, Form B13, Form B4, Form C1 and Form D. ${ }^{12}$

In Malaysia, the regulatory submission of the dossier has to be made only online via www.bpfk.gov.my as recommended by DCA. The submissions made by hard copy and by post are not acceptable. Before the dossier submission to DCA, the applicant must be registered with the Malaysian Register of Business. In case any technical assistance and help is required regarding the regulatory submission, the applicant can contact the Digicert Customer Service Department of DCA. The Centre inspects the premises of drug manufacturing for Compliance and Licensing (CCL) for verifying the compliance of Good Manufacturing Practices (GMP) for the approval of drug products to be marketed in Malaysia. After receiving the dossier of drug approval proposal, DCA conducts the review with a team of regulatory experts, and if satisfied, it sends the product registration number to the applicant. After paying drug product registration fees, the DCA approves the dossier and sends the drug registration certificate to the applicant.

In case if not satisfied with provided data, DCA asks for additional and other supporting information by notifying the applicant. The applicant has to submit the provided information within the six months of notification received, where further after receiving the same, the DCA sends the registration number. After the payment of drug registration fees, the dossier is approved, and the drug registration certificate will be issued to the applicant. Failure to submit provided information from the applicant within the time limit given by DCA results in the rejection of the drug submission proposal. ${ }^{9}$

In Vietnam, the drug registration dossiers are to be submitted to the DAV authority, first received by the Drug Registration Department (DRD). The related data received are prepared and compiled in sequential order of drug names and recorded in the logbook of DRD.

The DRD follow the first-in-first-out concept for the approval of submitted dossiers. A group of experts are assigned for the evaluation of the received dossier. Once all the members give the comments, the DRD compiles the comments as a document duly signed by the DAV Director and sends the letter to the applicant via e-mail.
The applicant will be informed to submit supplementary dossiers (if required) to the office of DRD after receiving the letter of comments. The supplementary dossier will be then further evaluated by the DRD's expert committee. Regarding the quality of the submitted dossiers, they will consult the DAV. Once the DAV is satisfied with the submitted data and information provided by the applicant, regulatory approval will be granted to the applicant, and a letter of product registration will be sent to the applicant. Rejection of submitted dossiers results with noncompliance of regulatory requirements of DAV regulations, and rejected dossiers are informed with rejection letter to the applicant. ${ }^{13}$

\section{CONCLUSION}

In the current study, three ASEAN countries, Indonesia, Malaysia and Vietnam, were selected as emerging regulatory markets. All follow both the ACTD and their country-specific regulations for generic drugs. These countries are paying more attention and providing more importance to healthcare, and also, there is also more demand for generic medicines and life-saving medicines. These ASEAN countries are not much regulated as like US, EU, Japan, Canada, etc. This could be due to a lack of harmonization of pharmaceutical regulations in the respective regions. If they have the regulations, some countries are failing to implement those regulations. Among the three ASEAN countries, Malaysia has well-implemented drug regulations and stringent rules concerning the quality and safety of generic drugs. This country values innovation and provide it with complete protection. As a result, there may not be many opportunities in this country unless small and medium scale generic companies manufacturing techniques comply with regulatory standards. The current study provides a simplified overview of generic drugs regulations and approval processes in three ASEAN countries, Indonesia, Malaysia and Vietnam.

\section{ACKNOWLEDGEMENT}

The authors would like to acknowledge the authorities of NITTE (Deemed to be University) and NGSM Institute of Pharmaceutical Sciences, Mangalore, for providing necessary support for preparing this manuscript.

\section{CONFLICT OF INTEREST}

The authors declare no conflicts of interest.

\section{ABBREVIATIONS}

ASEAN: Association of South East Asian Nations; ACTD: ASEAN Common Technical Document; CTD: Common Technical Document; DAV: Drug Administration of Vietnam; DCA: Drug Control Authority; DRD: Drug Registration Department; CCL: Centre for Compliance and Licensing; ICH: International Conference of Harmonization; GMP: Good Manufacturing Practices; STENIL: Standard Informasi Elecktroni; WHO: World Health Organisation; NA-DFC: National Agency of Drugs and Food Control; NPCB: National Pharmaceutical Control Bureau; ROB: Malaysian Register of Business; UHC: Universal Health Coverage.

\section{REFERENCES}

1. Kashyap P, Duggal E, Budhwar P, Badjatya JK. Marketing authorization of generic drug: Global issue and challenges. Int J Drug Regul Aff.2013;1(3):1-6. doi: 10.22270/ijdra.v1i3.5

2. ASEAN charter. Available from: https://asean.org/about-us/ [accessed on 20/01/ 2021] [cited 4/1/2022]

3. Tongia A. The drug regulatory landscape in the ASEAN region. Raps.org. 2018.

4. Patel R, Patel A, GohilT. Regulatory requirement for the approval of generic drug in Cambodia as per ASEAN Common Technical Dossier (ACTD). Int J Drug Regul Aff. 2018;6(2):67-71. doi: 10.22270/ijdra.v6i2.245.

5. Venkateswarlu B, Nagarjuna D, Ramaiah M, Nagabhushanam M, Akram MV. 
Regulatory requirements for the registration of generic solid orals in USA, Singapore, Malaysia and Thailand. J Glob Trends Pharm Sci. 2014;5(4):2225-32.

6. Handoo S, Khera D, Nandi P, Sahu S, Arora V. A comprehensive study on regulatory requirements for development and filing of generic drugs globally. Int J Pharma Investig. 2012;2(3):99-105. doi: 10.4103/2230-973X.104392.

7. Indonesia pharmaceutical regulatory update [cited 10/6/2021]. Available from: https://www.pacificbridgemedical.com/publication/indonesia-pharmaceuticalregulatory-update.

8. Malaysia drug registration guidance document (DRGD); 2021 [cited 20/6/2021]. Available from: https://www.npra.gov.my/index.php/en/component/ sppagebuilder/925-drug-reistartion-guidance-document-drgd.html.

9. National Pharmaceutical Regulatory Agency (NPRA); 2020 [cited Jan 30 2020]. Available from: https://www.npra.gov.my/index.php/en/.

10. Business monitor. Vietnam Pharmaceuticals and Healthcare Q1; 2021 [cited
4/6/2021]. Available from: https://www.marketresearch.com/Business-MonitorInternational-v304/Nietnam-Pharmaceuticals-Healthcare-01-13794059/.

11. Godiyal S. Regulatory requirements for preparation of dossier for registration of pharmaceutical products in ACTD and CTD format. Int J Drug Reg Affairs. 2019;7(2):51-61. doi: 10.22270/ijdra.v7i2.318.

12. Mohit, Deep A, Khurana G, Kumar J, Monga A. Comparison of Regulatory Requirements for Registration of Pharmaceutical Drugs in Asean and GCC Regions. App Clin Res Clin Trails Reg Affairs. 2019;6(1):62-70. doi: 10.2174/22 13476X06666190128145525.

13. Vietnam generic drug registration process [cited 18/10/2021]. Available from: https://credevo.com/articles/2021/01/15/vietnam-generic-drug-registrationprocess.

Article History: Received: 30-10-2021; Revised: 05-12-2021; Accepted: 20-12-2021

Cite this article: Sandeep DS, Sowmya CR, Narayanan AV, Gowrav MP. Generic Drugs Regulations and Registration in Indonesia, Malaysia and Vietnam: A Drug Regulatory Case Study. J Young Pharm. 2022;14(1):33-6. 